http://jmscr.igmpublication.org/home/ ISSN (e)-2347-176x ISSN (p) 2455-0450 crossref DOI: https://dx.doi.org/10.18535/jmscr/v8i5.62

\title{
Role of Sildenafil on Endometrial characters in ovulation induction cycle
}

\author{
Authors \\ Dr Y. Srilaxmi, $\mathrm{MD}^{1}$, Dr A. Vikram Arun, $\mathrm{MBBS}^{2}$, \\ Dr Alla Satyanarayana Reddy, $\mathrm{MD}^{3 *}$ \\ ${ }^{1}$ Associate Professor in Obstetrics \& Gynaecology, Prathima Institute of Medical Sciences, Karimnagar, \\ Telangana, India \\ ${ }^{2}$ Tutor in Radiology, Vinayaka Mission`s Medical College \& Hospital, Karaikal, Pondicherry, India \\ ${ }^{3}$ Professor in Obstetrics \& Gynaecology, Vinayaka Mission`s Research Foundation (DU), Karaikal, \\ Pondicherry, India \\ *Corresponding Author

\section{Dr Alla Satyanarayana Reddy}

Professor in OBG, Vinayaka Mission`s Medical College \& Hospital, Karaikal, Pondicherry, India. 609609

\begin{abstract}
Sildenafil causes vasodilatation by relaxing smooth muscles of blood vessels, enhances endometrial development. Improving endometrial thickness is one of the cornerstones in the management of infertility Aim of the Study: To evaluate the role of Sildenafil on endometrial characters in ovulation induction cycle. Materials and Methods: 50 infertile women with thin endometrium were randomly divided into two groups. Group A comprised of 25 women in whom clomiphene citrate $50 \mathrm{mg}$ daily from D2 to D6 along with estradiol valerate $2 \mathrm{mg}$ thrice daily from D2 and Group B of 25 women in whom clomiphene citrate $50 \mathrm{mg}$ daily from D2 to D6, estradiol valerate $2 \mathrm{mg}$ thrice daily from D2 and sildenafil citrate $25 \mathrm{mg}$ vaginally thrice daily from D7 to the day of ovulation trigger were given. Trans-vaginal ultrasound was done on alternate days from D8 of cycle for monitoring of follicular development and endometrial characters. HCG trigger was given once the dominant follicle reached $>18 \mathrm{~mm}$. Total three cycles of ovulation were studied.

Results: Monitoring of endometrial characters in all the ovulation induced cycles showed significant improvement in Group B. In Group B Mean endometrial thickness was $10.2 \pm 1.6 \mathrm{~mm}$ whereas it is $8.53 \pm 1.4$ mm in Group A; trilaminar pattern was $93.54 \%$ in group B compared to $40.29 \%$ in Group A; Zone 4 endometrium was $79.03 \%$ in Group B compared to $26.86 \%$ in Group A; clinical pregnancy rate per cycle was $20.96 \%$ in Group B compared to $13.45 \%$ in Group A.

Conclusion: Addition of vaginal Sildenafil to estradiol valerate has significant effect in improving endometrial characters and clinical pregnancy rates in ovulation induction cycles.

Keywords: Sildenafil; Estradiol; Endometrium.
\end{abstract}

\section{Introduction}

Endometrial thickness is one of the strongest predictors of implantation rate and ongoing success rates of pregnancy. Endometrial factors and implantation failure are the known causes of infertility. Endometrium less than $7 \mathrm{~mm}$ is a reliable sign of suboptimal implantation potential. Endometrial growth is dependent on uterine blood flow and angiogenesis. Endometrium is a dynamic 
tissue that responds to changing hormonal signals throughout the cycle

Thin endometrium can be due to various reasons mainly surgical procedures such as curettage, inadequate blood flow, Mullerian anomalies, use of clomiphene citrate, radiotherapy, recurrent infections. Hence adjuvants causing vasodilation have been suggested to be beneficial in women with thin endometrium.

Several agents such as aspirin, heparin, Larginine, vitamin E, pentoxyphilline, tocopherol, estrogen, sildenafil citrate and intrauterine infusion of growth factors were tried to achieve endometrial growth. The presence of a receptive endometrium is a major factor in determining conception. A good blood supply is considered as an essential requirement for implantation. Sildenafil citrate is a phosphodiesterase inhibitor that increases smooth muscle relaxation and vasodilation by preventing C GMP breakdown. Sildenafil potentiates uterine blood flow and in conjunction with estrogen, it increases estrogen induced proliferation of the endometrium.

\section{Aim of the Study}

To compare the effect of vaginal sildenafil and estradiol valerate to estradiol valerate alone in patients with clomiphene induced cycles in infertile women on endometrial thickness, blood flow and pregnancy rates

\section{Material and Methods}

This randomized study was conducted on infertile women attending an IVF centre in Hyderabad over a period of 2 years and 8 months from June 2016 to January 2019

Inclusion Criteria: Women less than 35 years of age; with primary or secondary infertility; with patent fallopian tubes; without any organic pelvic pathology; with endometrium thickness less than $7 \mathrm{~mm}$ on the day of ovulation or Day14 in previous clomiphene induced cycle.

Exclusion Criteria: Congenital uterine anomalies, acquired deformities of uterus [Asherman's Syndrome], tubal factors of infertility, sensitivity to sildenafil citrate, contra Indications for estrogen treatmen $\mathrm{t}$ [History of stroke, Deep Vein Thrombosis, Benign liver disease], moderate and severe male factor infertility.

After taking clearance from ethical committee and informed consent from the patient, 50 infertile women were taken up for study. Detailed history, general and local examination was done. Basic investigations along with hormonal profile [FSH, LH, Prolactin, AMH] on Day2 of cycle, TSH were done. Transvaginal Ultrasound of uterus and adnexa for any pelvic pathology, endometrial thickness on Day2 and Day14 was done. Those patients whose endometrium was less than $7 \mathrm{~mm}$ on Day14 were taken up for study in next cycle. Semen analysis was done to rule out male factor. Zone of vascular penetration into subendometrial and endometrial regions have been defined as :

Zone 1: A $2 \mathrm{~mm}$ thick area surrounding the hyperechoic outer layer of endometrium

Zone 2: Hyperechoic outer layer of endometrium

Zone 3: Hypoechoic inner layer of endometrium

Zone 4: Endometrial cavity

Patients were randomly divided into 2 groups, each consisting of 25 patients

A maximum of 3 cycles of ovulation induction were continued and followed up till 7 weeks of gestation

Group 1: 25 patients--Ovulation induction with Tab. Clomiphene Citrate 50mg daily from D2 to D6, along with Tab. Estradiol valerate $2 \mathrm{mg}$ thrice daily from D2 to D16

Group 2: 25 patients--Ovulation induction with Tab. Clomiphene Citrate 50mg daily from D2 to D6, along with Tab. Estradiol valerate $2 \mathrm{mg}$ thrice dailyfrom D2 to D16 and Tab. Sildenafil citrate $25 \mathrm{mg} 8^{\text {th }}$ hourly vaginally from D7 till HCG trigger.

In both the groups Ultrasound monitoring was done on alternate days from D8 onwards till HCG trigger and ovulation to check endometrial thickness, endometrial blood flow and follicular size. HCG trigger was given once the follicle reached more than $18 \mathrm{~mm}$. IUI was done in few 
patients if associated with mild male factor infertility

\section{Results}

Table 1

\begin{tabular}{|l|c|c|}
\hline & $\begin{array}{c}\text { Group A } \\
{[\mathrm{CC}+\text { estradiol }]}\end{array}$ & $\begin{array}{c}\text { Group B } \\
{[\mathrm{CC}+\text { estradiol + }} \\
\text { sildenafil }]\end{array}$ \\
\hline Median Age in years & 30.20 & 30.4 \\
\hline Primary infertility & $21[84 \%]$ & $22[88 \%]$ \\
\hline Secondary infertility & $4[16 \%]$ & $3[12 \%]$ \\
\hline Mean BMI[Kg/m2] & 28.3 & 27.9 \\
\hline $\begin{array}{l}\text { Median duration of } \\
\text { infertility }\end{array}$ & 4.26 years & 4.08 years \\
\hline
\end{tabular}

In Group A the Median age was 30.20 years, primary infertility in 21 [84\%] women, secondary infertility in 4[16\%] women, Mean BMI was 28.3 and median duration of infertility was 4.26 years. In Group B the Median age was 30.4 years, primary infertility in 22 [88\%] women, secondary infertility in 3[12\%] women, Mean BMI was 27.9 and Median duration of infertility was 4.08 years. The difference between both the groups is insignificant as regards to age, BMI, duration of infertility and type of infertility.

Table $21^{\text {st }}$ cycle of Ovulation Induction. USG monitoring on the day of ovulation trigger

\begin{tabular}{|l|c|c|}
\hline & $\begin{array}{c}\text { Group A } \\
{[\mathrm{CC}+\text { estradiol] }} \\
{[\mathrm{N}=25]}\end{array}$ & $\begin{array}{c}\text { Group B } \\
{[\mathrm{CC}+\text { estradiol }} \\
+ \text { +sildenafil }] \\
{[\mathrm{N}=25]}\end{array}$ \\
\hline $\begin{array}{l}\text { No of follicles more than } \\
18 \mathrm{~mm} \text { diameter }\end{array}$ & 1.28 & 1.36 \\
\hline Endometrial thickness & $8.6 \pm 1.4 \mathrm{~mm}$ & $10.2 \pm 1.8 \mathrm{~mm}$ \\
\hline Endometrial pattern & $10[40 \%]$ & $23[92 \%]$ \\
Trilaminar & $15[60 \%]$ & $2[8 \%]$ \\
Bilaminar & $1[4 \%]$ & $\mathrm{Nil}$ \\
Endometrial blood flow & $2[8 \%]$ & $1[4 \%]$ \\
Zone 1 & $13[52 \%]$ & $4[16 \%]$ \\
Zone 2 & $9[36 \%]$ & $20[80 \%]$ \\
Zone 3 & $2[8 \%]$ & $3[12 \%]$ \\
Zone 4 & & \\
\hline Clinical pregnancy & &
\end{tabular}

Average number of dominant follicles in Group A were 1.28, endometrial thickness $8.6 \pm 1.4 \mathrm{~mm}$, trilaminar endometrial pattern in $10[40 \%]$ women, zone 4 endometrium in 9[36\%] women where as in Group B average number of dominant follicles were 1.36, endometrial thickness $10.2 \pm 1.8 \mathrm{~mm}$, trilaminar endometrium in 23[92\%] women, zone 4 endometrium in 20[80\%] women. Two women from group A and three women from group B achieved clinical pregnancy.

Table $32^{\text {nd }}$ cycle of Ovulation Induction.USG Monitoring on the day of Ovulation trigger

\begin{tabular}{|l|c|c|}
\hline & $\begin{array}{c}\text { Group A } \\
{[\mathrm{CC}+\text { estradiol] }} \\
{[\mathrm{N}=23]}\end{array}$ & $\begin{array}{c}\text { Group B } \\
\text { [CC+estradiol } \\
\text { +sildenafil] } \\
{[\mathrm{N}=21]}\end{array}$ \\
\hline $\begin{array}{l}\text { No of follicles more than } \\
18 \mathrm{~mm} \text { diameter }\end{array}$ & 1.20 & 1.32 \\
\hline Endometrial thickness & $8.4 \pm 1.6 \mathrm{~mm}$ & $10.4 \pm 1.6 \mathrm{~mm}$ \\
\hline Endometrial pattern & $10[43.47 \%]$ & $20[95.23 \%]$ \\
Trilaminar & $13[56.52 \%]$ & $1[4.76 \%]$ \\
Bilaminar & & \\
\hline Endometrial blood flow & $1[4.34 \%]$ & $\mathrm{Nil}$ \\
Zone 1 & $3[13.04 \%]$ & $1[4.76 \%]$ \\
Zone 2 & $14[60.86 \%]$ & $4[19.04 \%]$ \\
Zone 3 & $5[21.73 \%]$ & $16[76.19 \%]$ \\
Zone 4 & $3[13.04 \%]$ & $5[23.80 \%]$ \\
\hline Clinical pregnancy & \multicolumn{2}{|c}{} \\
\hline
\end{tabular}

Total number of patients in Group A were 23 women and 21 patients in Group B. One patient didn't come for follow up. In Group A average number of dominant follicles were 1.20, endometrial thickness was $8.4 \pm 1.6 \mathrm{~mm}$, trilaminar endometrial pattern was noted in 10[43.47\%] women, zone 4 endometrial blood flow was noted in 5[21.73\%] women. In Group B average number of dominant follicles were 1.32, average endometrial thickness was $10.4 \pm 1.6 \mathrm{~mm}$, trilaminar endometrial pattern was seen in 20 [95.23\%] women, zone 4 endometrial blood flow was observed in 16 [76.19\%] women. Three out of 23 women in group A and 5 out of 21 women in group B achieved clinical pregnancy.

Table $43^{\text {rd }}$ cycle of Ovulation Induction.USG Monitoring on the day of Ovulation trigger

\begin{tabular}{|l|c|c|}
\hline & $\begin{array}{c}\text { Group A } \\
{[\mathrm{CC}+\text { estradiol] }} \\
{[\mathrm{N}=19]}\end{array}$ & $\begin{array}{c}\text { Group B } \\
{[\mathrm{CC}+\text { estradiol }} \\
+ \text { sildenafil }] \\
{[\mathrm{N}=16]}\end{array}$ \\
\hline $\begin{array}{l}\text { No of follicles more } \\
\text { than 18 mm diameter }\end{array}$ & 1.24 & 1.26 \\
\hline Endometrial thickness & $8.6 \pm 1.2 \mathrm{~mm}$ & $10 \pm 1.4 \mathrm{~mm}$ \\
\hline Endometrial pattern & $7[36.84 \%]$ & $15[93.75 \%]$ \\
Trilaminar & $12[63.15 \%]$ & $1[6.25 \%]$ \\
Bilaminar & $1[5.26 \%]$ & \\
\hline Endometrial blood flow & $3[15.78 \%]$ & $1[6.25 \%]$ \\
Zone 1 & $11[57.89 \%]$ & $2[12.5 \%]$ \\
Zone 2 & $4[21.05 \%]$ & $13[81.25 \%]$ \\
Zone 3 & $4[21.05 \%]$ & $5[31.25 \%]$ \\
Zone 4 & & \\
\hline Clinical pregnancy & &
\end{tabular}


Total number of patients in Group A were 19 patients and 16 patients in Group B. One patient didn't come for follow up In Group A. In Group A average number of dominant follicles were 1.24, average endometrial thickness was $8.6 \pm 1.2 \mathrm{~mm}$, trilaminar endometrial pattern was noted in $7[36.84 \%]$ patients, zone 4 endometrial blood flow was noted in 4[21.05\%] and 4 out of the nineteen women achieved clinical pregnancy. In Group B average number of dominant follicles were 1.26, average endometrial thickness was $10 \pm 1.4 \mathrm{~mm}$, trilaminar endometrial pattern was seen in $15[93.75 \%$ ] patients, zone 4 endometrial blood flow was observed in 13 [81.25\%] and five out of 16 women achieved clinical pregnancy.

Table 5 Summary of 3 cycles of Ovulation Induction

\begin{tabular}{|c|c|c|}
\hline & $\begin{array}{c}\text { Group A } \\
{[\mathrm{CC}+\text { estradiol }]} \\
{[\mathrm{N}=67]}\end{array}$ & $\begin{array}{c}\text { Group B } \\
\text { [CC+estradiol+ } \\
\text { sildenafil }] \\
{[N=62]}\end{array}$ \\
\hline $\begin{array}{l}\text { No of follicles more than } 18 \\
\text { mm diameter }\end{array}$ & 1.24 & 1.31 \\
\hline Endometrial thickness & $8.53 \pm 1.4 \mathrm{~mm}$ & $10.2 \pm 1.6 \mathrm{~mm}$ \\
\hline $\begin{array}{l}\text { Endometrial pattern } \\
\text { Trilaminar } \\
\text { Bilaminar }\end{array}$ & $\begin{array}{l}27[40.29 \%] \\
40[59.70 \%]\end{array}$ & $\begin{array}{c}58[93.54 \%] \\
4[6.45 \%]\end{array}$ \\
\hline $\begin{array}{l}\text { Endometrial blood flow } \\
\text { Zone } 1 \\
\text { Zone } 2 \\
\text { Zone } 3 \\
\text { Zone } 4\end{array}$ & $\begin{array}{c}3[4.47 \%] \\
8[11.94 \%] \\
38[56.71 \%] \\
18[26.86 \%]\end{array}$ & $\begin{array}{c}\text { Nil } \\
3[4.83 \%] \\
10[16.12 \%] \\
49[79.03 \%]\end{array}$ \\
\hline $\begin{array}{lll}\begin{array}{l}\text { Clinical } \\
\text { cycle }\end{array} & \text { pregnancy } & \text { per } \\
\end{array}$ & $9[13.45 \%]$ & $13[20.96 \%]$ \\
\hline $\begin{array}{l}\text { Total pregnancies in } 25 \\
\text { women, }(\%)\end{array}$ & $9(36 \%)$ & $13(52 \%)$ \\
\hline
\end{tabular}

Out of 67ovulation induced cycles in Group A average number of dominant follicles were 1.24, endometrial thickness was $8.53 \pm 1.4 \mathrm{~mm}$, trilaminar endometrial pattern was seen in $27[40.29 \%$ ] women, zone 4 endometrium in $18[26.86 \%]$ women and pregnancy per cycle was $13.45 \%$.In Group B out of 62 ovulation induced cycles average number of follicles were 1.31, endometrial thickness was $10.2 \pm 1.6 \mathrm{~mm}$, trilaminar endometrial pattern was seen in 58 [93.54\%] women, zone 4 endometrium in $49[79.03 \%]$ women and pregnancy per cycle was $20.96 \%$.

\section{Discussion}

Endometrium is a key factor for implantation. Clomiphene citrate is the first line of treatment for induction of ovulation. Despite good results reported with clomiphene for induction of ovulation a large proportion of females do not achieve pregnancy and the cause may be attributed to failure of implantation. Although most of the studies have compared estradiol or sildenafil alone with patients previous cycle as control, this study was done to compare the addition of sildenafil on an already established benefit of using estradiol valerate

We report statistically insignificant increase in mean number of follicles greater than $18 \mathrm{~mm}$ on the day of the HCG trigger. Ahmed et al., ${ }^{(11)}$ also reported mean increase in the number of follicles with sildenafil was insignificant.

In our study we found significant increase in the endometrial thickness to mean of $10.2 \mathrm{~mm}$ with a standard deviation of $1.6 \mathrm{~mm}$ in Group B compared to $8.53 \mathrm{~mm}$ with a standard deviation of $1.4 \mathrm{~mm}$ in Group A which is in accordance with Takasaki et al., (a prospective study of 61 patients with thin endometrium there was a significant improvement in endometrial thickness) $)^{(5)}$ which was also observed with Jerzal et al., ${ }^{(7)}$ Dalia Ibrahim et al., ${ }^{(12)}$ studies . Endometrial triple line [trilaminar pattern] in Group B was [93.54\%] compared to $40.29 \%$ in Group A which was also seen in Firouzabadi et al., (a study of endometrium thickness and triple line pattern with significantly higher with sildenafil and estradiol compared to estradiol alone) ${ }^{(6)}$.

In the present study there was endometrial blood flow zone 4 in $79.03 \%$ of women in Group B compared to $26.86 \%$ in Group A which is statistically significant. According to Mangal et al., ${ }^{(8)}$ there was a significant increase in endometrial thickness, endometrial pattern, sub endometrial blood flow in patients using sildenafil with eestradiol valerate. Mishra et al., ${ }^{(10)}$ reported statistically significant improvement in endometrial vascularity. In present clinical study clinical pregnancy rate per cycle was $20.96 \%$ in 
Group B where as $13.45 \%$ in Group A. Nine out of 25 women (36\%) in group A and 13 out of 25 $(52 \%)$ in group B had confirmed clinical pregnancy in the three months study period.

These significant results are due to direct effect of sildenafil on endometrial vascularity. In a prospective study, Wang et al., ${ }^{(13)}$ studied the endometrial thickness, echo pattern and blood flow on transvaginal sonography in 182 women 8 hours prior to HCG injection, they observed a higher clinical pregnancy rate and implantation in women with detectable blood flow. In Firouzabad et al., ${ }^{(6)}$ study clinical pregnancy rates were higher but not significant

The results in this study confirm the superiority of using vaginal sildenafil with estradiol for improving endometrial thickness, vascularity and pregnancy rates.

\section{Conclusion}

Addition of vaginal sildenafil citrate to estradiol valerate in ovulation induction cycles has better results in improving endometrial thickness, endometrial blood flow and pregnancy outcome as compared to estradiol valerate alone in women with anovulatory infertility.

\section{Conflict of Interest: Nil}

\section{References}

1. Sher G, Fisch JD. Vaginal sildenafil: A preliminary report of a novel method to improve Reference terine artery blood flow and endometrial development in patients undergoing IVF. HUM Reprod 2000,15; 806-9

2. Jyothi M Benni et al., An overview on sildenafil and female infertility Indian journal of Health sciences and biomedical research. KLEU 2016, vol 9, pg : 131-136

3. Shahinaz EI shourbagy et al., The role of sildenafil citrate suppositories on endometrial response [thickness and mean resistance index of endometrial spiral artery] in cases of unexplained infertility.
Menoufia medical journal, 2017,Vol 30, pg 343-349

4. Amr Mohamed S Abdel Hamid et al., effect of adding sildenafil to clomiphene citrate versus clomiphene citrate alone on endometrium in unexplained infertility. Obstetrics and gynecology International Journal 2017, Vol 7, issue 2

5. Takasaki Aetal, Endometrial growth and uterine blood flow: a pilot study for improving endometrial thickness in patients with a thin endometrium. Fertility and sterility, 93[6]: 1851-1858

6. Dehghani Firouzabadi R et al.,[2013]: Effect of sildenafil citrate on endometrial preparation and outcome of frozen thawed embryo transfer cycles: a randomized clinical trial, Iranian Journal of Reproductive Medicine 11[2]; 151-158

7. Jerzek et al., sildenafil citrate decreased natural killer cell activity and enhanced chance of successful pregnancy in women with history of recurrent miscarriage FertilSteril, 2008; 90; 1848-1853

8. Mangal et al., To study and compare the effect of vaginal sildenafil and estradiol valerate on endometrial thickness, blood flow and pregnancy rates in infertile women undergoing intrauterine insemination. Int $\mathrm{j}$ Reprodcontracept Obstet Gynecol., 2016; 5[7]; 2274-2277

9. Mohamed Ashraf Mohamed Farouk kortam at al., effect of estradiol valerate with and without oral sildenafil on endometrial thickness and pregnancy rates in infertile women EBWH Journal Nov 2018, Vol8,

10. Mishra V V Choudhary S et al, [2015] Vaginal Sildenafil: Role in improving endometrial blood flow in women undergoing IVF with frozen thawed embryo cycles. IJSR, 4[8] 292-4

11. Fahmy A A et al., [2015] The value of oral Sildenafil in the treatment of female 
infertility. A randomized controlled trial Life sci j, 12[4]; 78-82.

12. Dalia Ibrahim et al, the effect of Sildenafil versus estradiol on endometrial thickness and pattern in infertile females. EJPMR 2018,5[8], 581-584. 